\title{
Steady State Analysis of a Three Node Tandem Communication Network Model with DBA having Homogeneous Compound Poisson Direct Bulk Arrivals at Node 1 And Node 2
}

\author{
G. Rajendra Kumar \\ Dept. of CS \& SE, AUCE \\ ANDHRA UNIVERSITY \\ Visakhapatnam, INDIA
}

\author{
Kuda Nageswara Rao \\ Dept. of CS \& SE, AUCE \\ ANDHRA UNIVERSITY \\ Visakhapatnam, INDIA
}

\author{
K. Srinivas Rao \\ Dept. of Statistics \\ ANDHRA UNIVERSITY \\ Visakhapatnam, INDIA
}

\begin{abstract}
In this paper, a three stage communication network model with two stage homogeneous bulk arrivals and dynamic bandwidth allocation under equilibrium condition is developed and analyzed. Consider a Communication network in which three nodes are in tandem and the messages arrive to the first node are converted into number of packets and stored in first buffer connected to the first node. After transmitting from the first node, the messages arrive to the second node from first node and the messages which are directly arriving to the second node are converted into number of packets and stored in second buffer connected to the second node. After transmitting from the second node, the messages arrive to the third node are converted into number of packets and stored in third buffer connected to the third node. Dynamic Bandwidth Allocation (DBA) is the strategy that the transmission rate at each node is adjusted depending upon the content of the buffer at every packet transmission. It is assumed that the arrival of packets follow compound Poisson processes and the transmission completions at each node follow Poisson processes. The steady state analysis of this model is carried by assuming that the system is stable under equilibrium. This model is more accurately fit into the realistic situation of the communication network having a predecessor and successor nodes for the middle node. Using the difference-differential equations, the joint probability generating function of the number of packets in each buffer is derived. The performance measures like, the probability of emptiness of the three buffers, the mean content in each buffer, mean delays in buffers, throughput etc. are derived explicitly under equilibrium or steady state conditions. This network model is much useful in communication systems.
\end{abstract}

\section{Keywords}

Three stage communication networks, Dynamic bandwidth allocation, Batch arrivals and Steady state.

\section{INTRODUCTION}

Communication networks may conveniently be divided into three types, namely, Circuit switching, Message switching and Packet switching. In packet switching, the messages are decomposed into smaller pieces called packets each of which has a maximum length. The packets are numbered and addressed. The transmission takes place in the form of store and forward technique. The main advantage of packet switching is that the transmission delay is considerably reduced over circuit and message switching. It is generally known that packet switching gives better utilization over the circuit switching or message switching and yields relatively short network delay. The delay in packet switching can be reduced by utilizing statistical multiplexing in communication systems. For efficient utilization of the resources, the queuing models provide the basic frame work in communication networks. The communication networks are typically modeled as networks of inter connected queues by viewing the messages as customers, communication buffer as waiting line and all activities necessary for transmission of the messages as services. This representation is the most natural with respect to the actual operation of such systems. This sort of synchronization has an advantage of conceptual simplicity and great generality. This leads a communication network to view as tandem queuing system or serial queuing network. Several authors have studied the communication network as a tandem queue. They have considered that the independence assumption among the underlined service and arrival process [1-6]. However, in some communication systems like, store and forward communication network, the standard type of independence assumption is realistically inappropriate due to the fact that messages generally preserve their length as they traverse the network. The inter arrival and service sequence at queues, internal to the system, are thus dependent as they are the queuing processes at each of the nodes of the network through which the same messages are routed. These dependencies can have marked effect on system performance and must be accounted for any realistic analysis. Studies of Communication networks have found that large portions of the allocated bandwidth are highly underutilized. Frequency agile radios are cognitive radios that are capable of detecting idle bandwidth and opportunistically making use of it without causing harmful interference to the users. Communication network models play a predominant role in performance evaluation of many communication systems arising at places like, Telecommunications, Satellite communications, Computer communications, Broadband networks, Internet, ATM scheduling, etc,. For efficient design and evaluation, the communication networks are to be modeled with suitable characterization of the constituent processes. Due to unpredicted demand on transmission lines, congestion occurs in communication systems. The classic best-effort Internet is evolving into a versatile network that can provide various multimedia real time services in addition to the traditional data services and can improve the quality of service that guarantee to different users. The prime consideration in communication systems is to transmit the data/voice with high quality of service (QoS). To improve the QoS, packet switching gives better utilization over circuit or message switching and yields relatively short delay. Statistical multiplexing in communication networks can reduce the delays in packet switching. Many of the communication networks which supports Teleprocessing applications are mixed with statistical multiplexing and dynamic engineering skills. In store and 
forward communication systems, the transmitters are connected in tandem having more than one transmitter. When transmitters connected through buffers, the quality of service over transmission is much effected by the transmission strategies. To reduce congestion in buffers, the statistical multiplexing with load dependent strategy has been evolved through bit-dropping and flow control techniques with the assumption that the arrivals of packets to the buffers follow Poisson process $[7,8]$. However, in bit-dropping and flow control methodologies, the focus is on controlling arrival of packets by dropping the least significant bits. The extent of degradation of service quality is a function of the bits lost. To have an efficient transmission with high quality, it is needed to consider the variation on transmission rates based on content of the buffer. This type of adjusting the transmission rates depending upon the content of the buffer is known as dynamic bandwidth allocation (DBA).

Very little work has been reported in literature regarding communication networks with DBA with bulk arrivals. In store and forward communication networks, the messages arrived at the source are converted into a random number of packets depending upon the size of the message. As a result of it, the arrival of packets to the buffers is in bulk and the arrival process can be characterized with compound Poisson process. The compound Poisson process is capable of portraying the statistical nature of the bulk arrival of packets to the buffers and analyzes the communication systems more close to the reality. The compound Poisson process also includes the Poisson process as a particular case. Hence, in this paper, an attempt is made to evaluate the communication networks with bulk arrivals having DBA by developing and analyzing the associated Marchovian models $[9,10]$ have developed and analyzed some tandem communication network models with dynamic bandwidth allocation and homogeneous bulk arrivals. But, they considered only two nodes in tandem which does not resemble the realistic situations in the communication networks in reality. Generally, in any communication networks particularly in Point-to-Point communication networks, more than two data switching nodes are connected in series having a predecessor and a successor for the intermediate data switching node. Hence, an attempt is made to design, develop and analyze some communication network models with three data switching nodes connected in series or tandem. In this paper Steady state analysis of a three stage communication network with dynamic bandwidth allocation and batch arrivals at node 1 and node 2 embedded Markov chain techniques. Using the difference differential equations the performance measures of the communication network such as the joined probability generating function of the number of packets in each buffer, the probability of emptiness of buffers, mean number of packets in the buffers, mean delays in the buffers, throughput of the nodes are derived explicitly under equilibrium conditions. The performance evaluation of the network model is studies through numerical illustration.

\section{COMMUNICATION NETWORK MODEL UNDER STEADY STATE CONDITION}

Steady state analysis of a three stage communication network with dynamic bandwidth allocation and batch arrivals at node 1 and node 2 is developed and analyzed. Consider the messages arrive to the first node are converted a random number of packets and stored in the first buffer connected to the first node. The packets are forwarded to the second buffer connected to the second node after transmitting from the first node and the messages which are directly arrival to the second node. It is further considered that after transmitting from the second node the packets are forwarded to the third buffer connected to the third node. It is assumed that the arrival of packets to the first buffer is in batch with random batch size having the probability mass function $\left\{\mathrm{C}_{\mathrm{x}}\right\}$. It is considered that the random transmission is carried with dynamic bandwidth allocation in all the three nodes i.e. the transmission rate at each node is adjusted instantaneously and dynamically depending upon the content of the buffer connected to each node. This can be modeled as the transmission rates are linearly dependent on the content of the buffer. It is assumed that the arrival of packets following compound Poisson process with parameters $\lambda 1$ and $\lambda 2$ and the number of transmissions at node 1 , node 2 and node 3 follow Poisson process with parameters $\beta, \delta, \theta$ respectively. The operating principle of the queue is First in First out (FIFO). The schematic diagram represents the proposed communication network model is shown in Figure 1. For obtaining the performance of a communication network, it is needed to know the function form of the probability mass function of the number of packets that a message can be converted $(\mathrm{Cx})$. Using the difference differential equations, the Joint Probability Generating Function of the number of packets in the first, second and third buffers is derived as

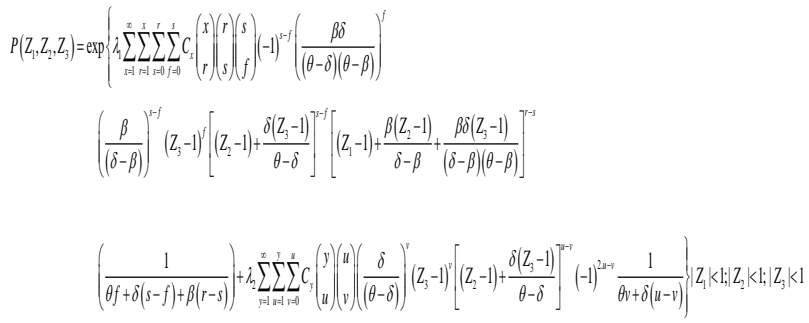

(1)

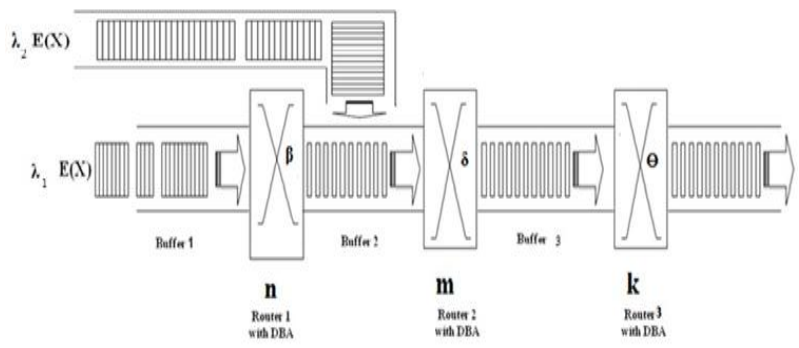

Fig 1: Three Node Tandem Communication network with dynamic bandwidth allocation and batch arrivals atNode1 and Node2

\section{PERFORMANCE MEASURES OF THE PROPOSED COMMUNICATION NETWORK}

The probability of emptiness of the whole network is

$$
\begin{aligned}
& P_{0,0, \theta}=\exp \left\{\lambda_{1} \sum_{x=1}^{\infty} \sum_{i=1}^{x} \sum_{i=0}^{x} \sum_{j=0}^{s} C_{x}\left(\begin{array}{l}
x \\
r
\end{array}\right)\left(\begin{array}{l}
r \\
s
\end{array}\right)\left(\begin{array}{l}
s \\
f
\end{array}\right)^{(-1)^{s}}\left(\frac{\beta \delta}{(\theta-\delta)(\theta-\beta)}\right)^{\prime}\right. \\
& \left(\frac{\beta}{\delta-\beta}\right)^{x-f}\left(\frac{\theta}{\delta-\theta}\right)^{\alpha-f}\left[-1-\frac{\beta}{\delta-\beta}-\frac{\beta \delta}{(\delta-\beta)(\theta-\beta)}\right]^{r-1} \\
& \left.\frac{1}{\theta f+(\delta)(s-f)+(\beta)(r-s)}+\lambda 2 \sum_{y=1}^{\infty} \sum_{v=1}^{s} \sum_{v=0}^{n} C_{y}\left(\begin{array}{l}
y \\
u
\end{array}\right)\left(\begin{array}{l}
u \\
v
\end{array}\right)\left(\frac{\delta}{(\theta-\delta)}\right)^{v}(-1)^{2 u} \frac{1}{\theta_{v}+\delta(u-v)}\right\}
\end{aligned}
$$

The probability generating function of the number of packets in the first buffer is 
$P\left(Z_{1}\right)=\exp \left\{\lambda_{1} \sum_{x=1}^{\infty} \sum_{r=1}^{x} C_{x}\left(\begin{array}{l}x \\ r\end{array}\right)\left(Z_{1}-1\right)^{r}\left(\frac{1}{\beta r}\right)\right\} ;\left|Z_{1}\right|<1$

(3)

The probability that the first buffer is empty

$$
P_{0 . .}=\exp \left\{\lambda_{1} \sum_{x=1}^{\infty} \sum_{r=1}^{x} C_{x}\left(\begin{array}{l}
x \\
r
\end{array}\right)(-1)^{r}\left(\frac{1}{\beta r}\right)\right\}
$$

The probability generating function of the number of packets in the second buffer is

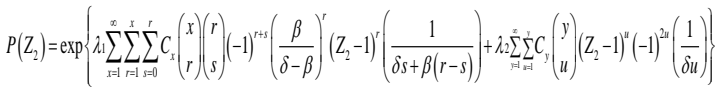

$$
\begin{aligned}
& ;\left|Z_{2}\right| k 1
\end{aligned}
$$

The probability that the second buffer is empty

$$
P_{\Delta t}=\exp \left\{\lambda_{\lambda} \sum_{x=1}^{\infty} \sum_{r=1}^{x} \sum_{s=0}^{r} C_{x}\left(\begin{array}{l}
x \\
r
\end{array}\right)\left(\begin{array}{l}
r \\
s
\end{array}\right)(-1)^{r+s}\left(\frac{\beta}{\delta-\beta}\right)^{r}\left(\frac{1}{\delta s+\beta(r-s)}\right)+\lambda_{2} \sum_{r=1}^{x} \sum_{i=1} C_{y}\left(\begin{array}{l}
y \\
u
\end{array}\right)(-1)^{2 u}\left(\frac{1}{\delta u}\right)\right\}
$$

The probability generating function of the number of packets in the third buffer is

$$
\begin{gathered}
P\left(Z_{3}\right)=\exp \left\{\lambda_{1} \sum_{x=1}^{\infty} \sum_{r=1}^{x} \sum_{s=0}^{r} \sum_{f=0}^{s} C_{x}\left(\begin{array}{l}
x \\
r
\end{array}\right)\left(\begin{array}{l}
r \\
s
\end{array}\right)\left(\begin{array}{l}
s \\
f
\end{array}\right)(-1)^{r+s-f}\left(\frac{\beta \delta}{(\theta-\delta)(\theta-\beta)}\right)^{f}\left(\frac{\beta \delta}{(\delta-\beta)(\theta-\delta)}\right)^{s-f}\left[\frac{\beta \delta}{(\delta-\beta)(\theta-\beta)}\right]^{r-s}\left(z_{3}-1\right)^{r}\right. \\
\left.\left(\frac{1}{\theta f+\delta(s-f)+\beta(r-s)}\right)+\lambda_{2} \sum_{y=1}^{\infty} \sum_{u=1}^{y} \sum_{v=0}^{u} C_{y}\left(\begin{array}{l}
y \\
u
\end{array}\right)\left(\begin{array}{l}
u \\
v
\end{array}\right)^{\left(z_{3}-1\right)^{u}}\left(\frac{\delta\left(z_{3}-1\right)}{(\theta-\delta)}\right)^{u}(-1)^{2 u-v}\left(\frac{1}{\theta v+\delta(u-v)}\right)\right\}
\end{gathered}
$$

The probability that the third buffer is empty

$$
\begin{gathered}
P_{* 00}=\exp \left\{\lambda_{1} \sum_{x=1}^{\infty} \sum_{r=1}^{x} \sum_{s=0}^{r} \sum_{f=0}^{s} C_{x}\left(\begin{array}{l}
x \\
r
\end{array}\right)\left(\begin{array}{l}
r \\
s
\end{array}\right)\left(\begin{array}{l}
s \\
f
\end{array}\right)(-1)^{r s-s-f}\left(\frac{\beta \delta}{(\theta-\delta)(\theta-\beta)}\right)^{f}\left(\frac{\beta \delta}{(\delta-\beta)(\theta-\delta)}\right)^{s-f}\left[\frac{\beta \delta}{(\delta-\beta)(\theta-\beta)}\right]^{r-s}\right. \\
\left.\left(\frac{1}{\theta f+\delta(s-f)+\beta(r-s)}\right)+\lambda_{2} \sum_{y=1}^{\infty} \sum_{u=1}^{x} \sum_{v=0}^{u} C_{y}\left(\begin{array}{l}
y \\
u
\end{array}\right)\left(\begin{array}{l}
u \\
v
\end{array}\right)\left(\frac{\delta}{(\theta-\delta)}\right)^{u}(-1)^{3 u-v}\left(\frac{1}{\theta v+\delta(u-v)}\right)\right\}
\end{gathered}
$$

The mean number of packets in the first buffer is

$L_{1}=\frac{\lambda_{1}}{\beta}\left(\sum_{x=1}^{\infty} x C_{x}\right)$

The mean number of packets in the second buffer is

$L_{2}=\lambda_{1}\left(\sum_{x=1}^{\infty} x C_{x}\right)[\delta]+\frac{\lambda_{2}}{\delta}\left(\sum_{y=1}^{\infty} y C_{y}\right)$

The mean number of packets in the third buffer is

$$
\begin{aligned}
L_{3}=\lambda_{1}\left(\sum_{x=1}^{\infty} x C_{x}\right)\left[\frac{\beta \delta}{(\delta-\beta)(\theta-\beta) \beta}-\frac{\beta \delta}{(\delta-\beta)(\theta-\delta) \delta}\right. \\
\left.+\frac{\beta \delta}{\theta(\theta-\beta)(\theta-\delta)}\right]+\lambda_{2}\left(\sum_{y=1}^{\infty} y C_{y}\right)\left(\frac{1}{\theta}\right)
\end{aligned}
$$

The probability that there is at least one packet in the first node is

$U_{1}=1-\exp \left\{\lambda_{1} \sum_{x=1}^{\infty} \sum_{r=1}^{x} C_{x}\left(\begin{array}{l}x \\ r\end{array}\right)(-1)^{r}\left(\frac{1}{\beta r}\right)\right\}$

The probability that there is at least one packet in the second node is

$$
\begin{aligned}
U_{2} & =1-P_{\text {sve }} \\
& =1-\exp \left(\lambda_{1} \sum_{x=1}^{\infty} \sum_{r=1}^{x} \sum_{s=0}^{x} C_{x}\left(\begin{array}{l}
x \\
r
\end{array}\right)\left(\begin{array}{l}
r \\
s
\end{array}\right)(-1)^{r+s}\left(\frac{\beta}{\delta-\beta}\right)^{r}\left(\frac{1}{\delta s+\beta(r-s)}\right)+\lambda_{2} \sum_{y=1}^{x} \sum_{y=1} C_{y}\left(\begin{array}{l}
y \\
u
\end{array}\right)(-1)^{3 u}\left(\frac{1}{\delta u}\right)\right\}
\end{aligned}
$$

The probability that there is at least one packet in the third node is

$$
\begin{aligned}
& U_{3}=1-P_{m 0}
\end{aligned}
$$

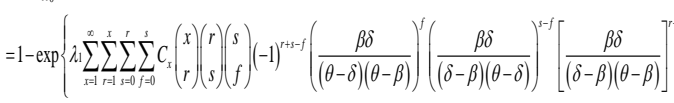

$$
\begin{aligned}
& \left.\left(\frac{1}{\theta f+\delta(s-f)+\beta(r-s)}\right)+\lambda_{2} \sum_{y=1}^{x} \sum_{u=1}^{\delta} \sum_{y=0}^{u} C_{y}\left(\begin{array}{l}
y \\
u
\end{array}\right)\left(\begin{array}{l}
u \\
v
\end{array}\right)\left(\frac{\delta}{(\theta-\delta)}\right)^{u}(-1)^{3 u-v}\left(\frac{1}{\theta v+\delta(u-v)}\right)\right\}
\end{aligned}
$$

The mean number of packets in the whole network is $\mathrm{L}=\mathrm{L}_{1}+\mathrm{L}_{2}+\mathrm{L}_{3}$

(15)

Throughput of the first node is

$$
\text { Thp1 }=\beta U_{1}=\beta\left[1-P_{O} . .\right]
$$

Throughput of the second node is

Thp2 $=\delta \mathrm{U}_{2}=\delta\left(1-\mathrm{P}_{.0 .}\right)$

Throughput of the third node is (18)

Thp3 $=\theta \mathbf{U}_{3}=\theta\left(1-\mathbf{P}_{. .0}\right)$

The mean delay in the first buffer is

$$
\begin{aligned}
W_{1} & =\frac{L_{1}}{\beta\left(1-P_{0 . .)}\right)} \\
& =\frac{\frac{\lambda_{1}}{\beta}\left(\sum_{x=1}^{\infty} x C_{x}\right)}{\beta\left\{1-\exp \left\{\lambda_{1} \sum_{x=1}^{\infty} \sum_{r=1}^{x} C_{x}\left(\begin{array}{l}
x \\
r
\end{array}\right)(-1)^{r}\left(\frac{1}{\beta r}\right)\right\}\right\}}
\end{aligned}
$$

The mean delay in the second buffer is

$$
\begin{aligned}
& W_{2}=\frac{L_{2}}{\delta\left(1-P_{\text {ot. }}\right)}
\end{aligned}
$$

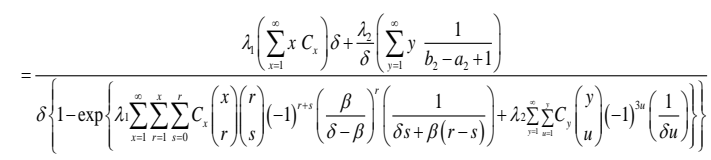

The mean delay in the third buffer is 
$W_{3}=\frac{L_{3}}{\theta\left(1-P_{\text {wo }}\right)}$

$$
\begin{aligned}
& \lambda_{1}\left(\sum_{x=1}^{x} x C_{x}\right)\left[\frac{\beta \delta}{[\delta-\beta)(\theta-\beta)(\alpha+\beta)}-\frac{\beta \delta}{(\delta-\beta)(\theta-\delta)(\gamma+\delta)}\right.
\end{aligned}
$$

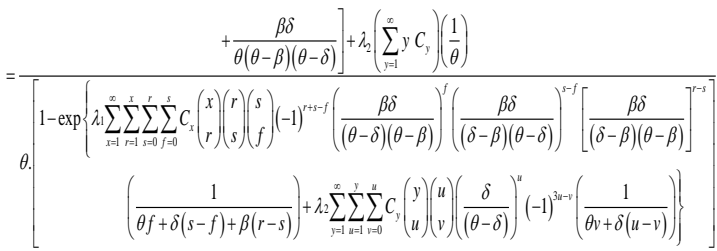

The variance of the number of packets in the first buffer is

$V_{1}=\frac{\lambda_{1}}{2 \beta}\left(\sum_{x=1}^{\infty} x(x-1) C_{x}\right)+\frac{\lambda_{1}}{\beta}\left(\sum_{x=1}^{\infty} x C_{x}\right)$

The variance of the number of packets in the second buffer is

$$
\begin{aligned}
V_{2}= & \lambda_{1}\left(\sum_{x=1}^{\infty} x(x-1) C_{x}\right)\left(\frac{\beta}{\beta-\delta}\right)^{2}\left[\left(\frac{1}{2 \beta}\right)-2\left(\frac{1}{(\beta+\delta)}\right)+\left(\frac{1}{2 \delta}\right)\right] \\
& +\lambda_{2}\left(\sum_{y=1}^{\infty} y(y-1) C_{y}\right)\left(\frac{1}{2 \delta}\right)+\lambda_{1}\left(\sum_{x=1}^{\infty} x C_{x}\right) \frac{1}{\delta} \\
& +\frac{\lambda_{2}}{\delta}\left(\sum_{y=1}^{\infty} y C_{y}\right)
\end{aligned}
$$

The variance of the number of packets in the third buffer is

$$
\begin{aligned}
V_{3}= & \lambda_{1}(\beta \delta)^{2}\left(\sum_{x=1}^{\infty} x(x-1) C_{x}\right)\left\{\left[\frac{1}{(\delta-\beta)(\theta-\beta)}\right]^{2}\left(\frac{1}{2 \beta}\right)-2\left(\frac{1}{\delta-\beta}\right)^{2}\right. \\
& {\left[\frac{1}{(\theta-\delta)(\theta-\beta)}\right]\left(\frac{1}{\beta+\delta}\right)+2\left(\frac{1}{\theta-\beta}\right)^{2}\left[\frac{1}{(\delta-\beta)(\theta-\delta)}\right] } \\
& \left(\frac{1}{\beta+\theta}\right)+\left[\frac{1}{(\delta-\beta)(\theta-\delta)}\right]^{2}\left(\frac{1}{2 \delta}\right)-2\left[\frac{1}{\theta-\delta}\right]^{2} \\
+ & \lambda_{2}\left[\frac{1}{\delta-\theta}\right]^{2}\left(\sum_{y=1}^{\infty} y(y-1) C_{y}\right)\left[\left(\frac{1}{2 \delta}\right)-\left(\frac{1}{(\delta+\theta)}\right)+\left(\frac{1}{2 \theta}\right)\right] \\
& +\lambda_{1} \beta \delta\left(\sum_{x=1}^{\infty} x C_{x}\right)\left[\left(\frac{1}{(\theta+\delta)}\right)+\left[\frac{1}{(\delta-\beta)(\theta-\beta) \beta}\right)-\left(\frac{1}{(\delta-\beta)(\theta-\delta) \delta}\right)\right. \\
& \left.+\left(\frac{1}{(\theta-\delta)(\theta-\beta) \theta}\right)\right]+\lambda_{2}\left(\sum_{y=1}^{\infty} y C_{y}\right)\left(\frac{1}{\theta}\right)
\end{aligned}
$$

The coefficient of variation of the number of packets in the first node is

$\mathrm{CV}_{1}=\frac{\sqrt{\mathrm{V}_{1}}}{\mathrm{~L}_{1}}$

The coefficient of variation of the number of packets in the second node is

$\mathrm{CV}_{2}=\frac{\sqrt{\mathrm{V}_{2}}}{\mathrm{~L}_{2}}$
The coefficient of variation of the number of packets in the third node is

$\mathrm{CV}_{3}=\frac{\sqrt{\mathrm{V}_{3}}}{\mathrm{~L}_{3}}$

\section{PERFORMANCE MEASURES OF THE PROPOSED NETWORK MODEL WITH UNIFORM BATCH SIZE DISTRIBUTION}

It is assumed the batch size of the packets follows a uniform distribution and the probability distribution of the batch size of the packets in a message is $C_{k}=1 /\{(b-a)+1\}$, for $k=a$, $\mathrm{a}+1, \ldots, \mathrm{b}$. and the mean number of packets in a message is $(a+b) / 2$ and its variance is $(1 / 12)\left[(b-a+1)^{2}-1\right]$ Substituting the value of $C_{x}$ in the equation (1), we get the Joint Probability Generating Function of the number of packets in the whole networks is

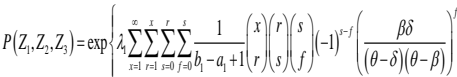

$$
\begin{aligned}
& \left(\frac{\beta}{(\delta-\beta)}\right)^{\alpha-\gamma}\left(Z_{3}-1\right)^{\gamma}\left[\left(Z_{2}-1\right)+\frac{\delta\left(Z_{3}-1\right)^{\gamma-\gamma}}{\theta-\delta}\right]^{\alpha}\left[\left(Z_{1}-1\right)+\frac{\beta\left(Z_{2}-1\right)}{\delta-\beta}+\frac{\beta \delta\left(Z_{3}-1\right)}{(\delta-\beta)(\theta-\beta)}\right]^{r-s}
\end{aligned}
$$

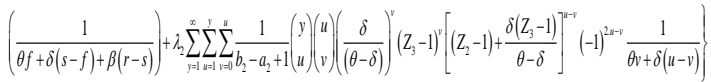

The probability of emptiness of the whole network is

$$
\begin{aligned}
& P_{0,0,0}=\exp \left\{\lambda_{1} \sum_{x=1}^{\infty} \sum_{r=1}^{x} \sum_{s=0}^{r} \sum_{f=0}^{s} \frac{1}{b_{1}-a_{1}+1}\left(\begin{array}{l}
x \\
r
\end{array}\right)\left(\begin{array}{l}
r \\
s
\end{array}\right)\left(\begin{array}{l}
s \\
f
\end{array}\right)(-1)^{s}\left(\frac{\beta \delta}{(\theta-\delta)(\theta-\beta)}\right)^{f}\right. \\
& \left(\frac{\beta}{\delta-\beta}\right)^{s-f}\left(\frac{\theta}{\delta-\theta}\right)^{s-f}\left[-1-\frac{\beta}{\delta-\beta}-\frac{\beta \delta}{(\delta-\beta)(\theta-\beta)}\right]^{r-1} \\
& \left.\frac{1}{\theta f+(\delta)(s-f)+(\beta)(r-s)}+\lambda_{2} \sum_{y=1}^{\infty} \sum_{u=1}^{v} \sum_{v=0}^{u} \frac{1}{b_{2}-a_{2}+1}\left(\begin{array}{l}
y \\
u
\end{array}\right)\left(\begin{array}{l}
u \\
v
\end{array}\right)\left(\frac{\delta}{(\theta-\delta)}\right)^{v}(-1)^{2 u} \frac{1}{\theta v+\delta(u-v)}\right\}
\end{aligned}
$$

The probability generating function of the number of packets in the first buffer is

$$
P\left(Z_{1}\right)=\exp \left\{\lambda_{1} \sum_{x=1}^{\infty} \sum_{r=1}^{x} \frac{1}{b_{1}-a_{1}+1}\left(\begin{array}{l}
x \\
r
\end{array}\right)\left(Z_{1}-1\right)^{r}\left(\frac{1}{\beta r}\right)\right\} ; \text { for }\left|Z_{1}\right|<1
$$

The probability that the first buffer is empty

$$
P_{0 . .}=\exp \left\{\lambda_{1} \sum_{x=1}^{\infty} \sum_{r=1}^{x} \frac{1}{b_{1}-a_{1}+1}\left(\begin{array}{l}
x \\
r
\end{array}\right)(-1)^{r}\left(\frac{1}{\beta r}\right)\right\}
$$

The probability generating function of the number of packets in the second buffer is

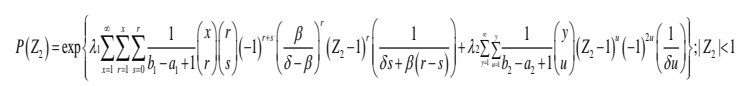

The probability that the second buffer is empty

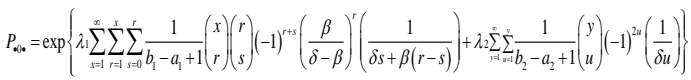


The probability generating function of the number of packets in the third buffer is

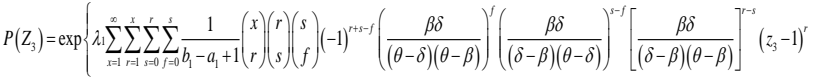

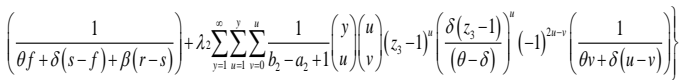

The probability that the third buffer is empty

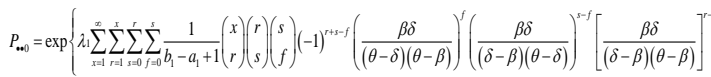

$$
\begin{aligned}
& \left.\left(\frac{1}{\theta f+\delta(s-f)+\beta(r-s)}\right)+\lambda_{2} \sum_{v=1}^{x} \sum_{u=1}^{\infty} \sum_{i=0}^{n} \frac{1}{b_{2}-a_{2}+1}\left(\begin{array}{l}
y \\
u
\end{array}\right)\left(\begin{array}{l}
u \\
v
\end{array}\right)\left(\frac{\delta}{(\theta-\delta)}\right)^{u}(-1)^{3-v-v}\left(\frac{1}{\theta v+\delta(u-v)}\right)\right)
\end{aligned}
$$

The mean number of packets in the first buffer is

$$
L_{1}=\frac{\lambda_{1}}{\beta}\left(\sum_{x=1}^{\infty} x \frac{1}{b_{1}-a_{1}+1}\right)
$$

The mean number of packets in the second buffer is

$$
L_{2}=\lambda_{1}\left(\sum_{x=1}^{\infty} x \frac{1}{b_{1}-a_{1}+1}\right)[\delta]+\frac{\lambda_{2}}{\delta}\left(\sum_{y=1}^{\infty} y \frac{1}{b_{2}-a_{2}+1}\right)
$$

The mean number of packets in the third buffer is

$$
\begin{aligned}
L_{3}= & \lambda_{1}\left(\sum_{x=1}^{\infty} x \frac{1}{b_{1}-a_{1}+1}\right)\left[\frac{\beta \delta}{(\delta-\beta)(\theta-\beta)(\alpha+\beta)}-\frac{\beta \delta}{(\delta-\beta)(\theta-\delta)(\gamma+\delta)}\right. \\
& \left.+\frac{\beta \delta}{\theta(\theta-\beta)(\theta-\delta)}\right]+\lambda_{2}\left(\sum_{y=1}^{\infty} y \frac{1}{b_{2}-a_{2}+1}\right)\left(\frac{1}{\theta}\right)
\end{aligned}
$$

The probability that there is at least one packet in the first node is

$$
U_{1}=1-\exp \left\{\lambda_{1} \sum_{x=1}^{\infty} \sum_{r=1}^{x} \frac{1}{b_{1}-a_{1}+1}\left(\begin{array}{l}
x \\
r
\end{array}\right)(-1)^{r}\left(\frac{1}{\beta r}\right)\right\}
$$

The probability that there is at least one packet in the second node is

$U_{2}=1-P_{\text {vev }}$

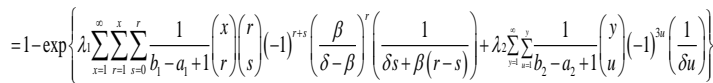

The probability that there is at least one packet in the third node is,

$$
\begin{aligned}
& U_{3}=1-P_{w 0} \\
& =1-\exp \left\{\lambda_{1} \sum_{x=1}^{x} \sum_{r=1}^{x} \sum_{=0=f=0}^{r} \sum_{f=0}^{s} \frac{1}{b_{1}-a_{1}+1}\left(\begin{array}{l}
x \\
r
\end{array}\right)\left(\begin{array}{l}
r \\
s
\end{array}\right)\left(\begin{array}{l}
s \\
f
\end{array}\right)(-1)^{r+s-f}\left(\frac{\beta \delta}{(\theta-\delta)(\theta-\beta)}\right)^{f}\left(\frac{\beta \delta}{(\delta-\beta)(\theta-\delta)}\right)^{s-f}\left[\frac{\beta \delta}{(\delta-\beta)(\theta-\beta)}\right]^{r-1}\right. \\
& \left.\left(\frac{1}{\theta f+\delta(s-f)+\beta(r-s)}\right)+\lambda_{2} \sum_{j=1}^{\infty} \sum_{u=1}^{x} \sum_{v=0}^{u} \frac{1}{b_{2}-a_{2}+1}\left(\begin{array}{l}
y \\
u
\end{array}\right)\left(\begin{array}{l}
u \\
v
\end{array}\right)\left(\frac{\delta}{(\theta-\delta)}\right)^{u}(-1)^{3 u-v}\left(\frac{1}{\theta v+\delta(u-v)}\right)\right\}
\end{aligned}
$$

The mean number of packets in the whole network is $\mathrm{L}=\mathrm{L}_{1}+\mathrm{L}_{2}+\mathrm{L}_{3}$

Throughput of the first node is

$\mathrm{Thp} 1=\beta \mathrm{U}_{1}=\beta\left[1-\mathbf{P}_{\mathrm{O} . .}\right]$

Throughput of the second node is $\mathrm{Thp} 2=\delta \mathrm{U}_{2}=\delta\left(1-\mathrm{P}_{0 .}\right)$

(44)

Throughput of the third node is

Thp $3=\theta \mathrm{U}_{3}=\theta\left(1-\mathrm{P}_{.0}\right)$

(45)

The mean delay in the first buffer is

$$
\begin{aligned}
W_{1} & =\frac{L_{1}}{\beta\left(1-P_{0 . .}\right)} \\
& =\frac{\frac{\lambda_{1}}{\beta}\left(\sum_{x=1}^{\infty} x \frac{1}{b_{1}-a_{1}+1}\right)}{\beta\left\{1-\exp \left\{\lambda_{1} \sum_{x=1}^{\infty} \sum_{r=1}^{x} \frac{1}{b_{1}-a_{1}+1}\left(\begin{array}{l}
x \\
r
\end{array}\right)(-1)^{r}\left(\frac{1}{\beta r}\right)\right\}\right\}}
\end{aligned}
$$

The mean delay in the second buffer is $W_{2}=\frac{L_{2}}{\delta\left(1-P_{\text {s.0 }}\right)}$

$$
\begin{aligned}
& \lambda_{1}\left(\sum_{x=1}^{\infty} x \frac{1}{b_{1}-a_{1}+1}\right)\left[\left(\frac{1}{\delta}\right)\right]+\frac{\lambda_{2}}{\delta}\left(\sum^{\infty} y \frac{1}{b_{2}-a_{2}+1}\right)
\end{aligned}
$$

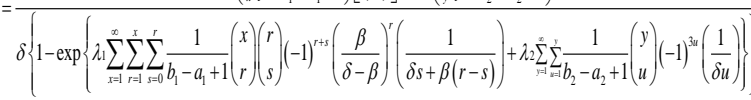

The mean delay in the third buffer is

$W_{3}=\frac{L_{3}}{\theta\left(1-P_{., 0}\right)}$

$$
\begin{aligned}
& \lambda_{1}\left(\sum_{x=1}^{x} x \frac{1}{b_{1}-a_{1}+1}\right]\left[\frac{\beta \delta}{(\delta-\beta)(\theta-\beta)(\alpha+\beta)}-\frac{\beta \delta}{(\delta-\beta)(\theta-\delta)(\gamma+\delta)}\right.
\end{aligned}
$$

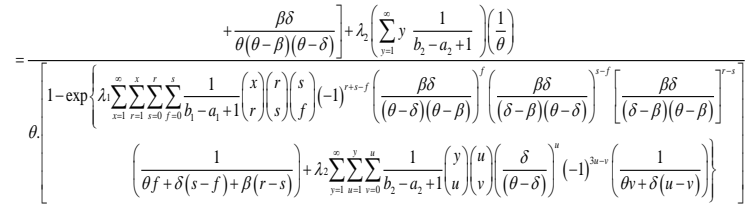

The variance of the number of packets in the first buffer is $V_{1}=\frac{\lambda_{1}}{2 \beta}\left(\sum_{x=1}^{\infty} x(x-1) \frac{1}{b_{1}-a_{1}+1}\right)+\frac{\lambda_{1}}{\beta}\left(\sum_{x=1}^{\infty} x \frac{1}{b_{1}-a_{1}+1}\right)$

(49)

The variance of the number of packets in the second buffer is

$$
\begin{aligned}
V_{2}= & \lambda_{1}\left(\sum_{x=1}^{\infty} x(x-1) \frac{1}{b_{1}-a_{1}+1}\right)\left(\frac{\beta}{\beta-\delta}\right)^{2}\left[\left(\frac{1}{2 \beta}\right)-2\left(\frac{1}{(\beta+\delta)}\right)+\left(\frac{1}{2 \delta}\right)\right] \\
& +\lambda_{2}\left(\sum_{y=1}^{\infty} y(y-1) \frac{1}{b_{2}-a_{2}+1}\right)\left(\frac{1}{2 \delta}\right)+\lambda_{1}\left(\sum_{x=1}^{\infty} x \frac{1}{b_{1}-a_{1}+1}\right) \frac{1}{\delta} \\
& +\frac{\lambda_{2}}{\delta}\left(\sum_{y=1}^{\infty} y \frac{1}{b_{2}-a_{2}+1}\right)
\end{aligned}
$$

The variance of the number of packets in the third buffer is

$$
\begin{aligned}
V_{3} & =\lambda_{1}(\beta \delta)^{2}\left(\sum_{x=1}^{\infty} x(x-1) \frac{1}{b_{1}-a_{1}+1}\right)\left\{\left[\frac{1}{(\delta-\beta)(\theta-\beta)}\right]^{2}\left(\frac{1}{2 \beta}\right)-2\left(\frac{1}{\delta-\beta}\right)^{2}\right. \\
& {\left[\frac{1}{(\theta-\delta)(\theta-\beta)}\right]\left(\frac{1}{\beta+\delta}\right)+2\left(\frac{1}{\theta-\beta}\right)^{2}\left[\frac{1}{(\delta-\beta)(\theta-\delta)}\right] } \\
& \left(\frac{1}{\beta+\theta}\right)+\left[\frac{1}{(\delta-\beta)(\theta-\delta)}\right]^{2}\left(\frac{1}{2 \delta}\right)-2\left[\frac{1}{\theta-\delta}\right]^{2} \\
& {\left.\left[\frac{1}{(\delta-\beta)(\theta-\beta)}\right]\left(\frac{1}{(\theta+\delta)}\right)+\left[\frac{1}{(\theta-\delta)(\theta-\beta)}\right]^{2}\left(\frac{1}{\theta}\right)\right\} } \\
& +\lambda_{2}\left[\frac{\delta}{\delta-\theta}\right]^{2}\left(\sum_{y=1}^{\infty} y(y-1) \frac{1}{b_{2}-a_{2}+1}\right)\left[\left(\frac{1}{2 \delta}\right)-\left(\frac{1}{(\delta+\theta)}\right)+\left(\frac{1}{2 \theta}\right)\right] \\
& +\lambda_{1} \beta \delta\left(\sum_{x=1}^{\infty} x \frac{1}{b_{1}-a_{1}+1}\right)\left[\left(\frac{1}{(\delta-\beta)(\theta-\beta) \beta}\right)-\left(\frac{1}{(\delta-\beta)(\theta-\delta) \delta}\right)\right. \\
& \left.+\left(\frac{1}{(\theta-\delta)(\theta-\beta) \theta}\right)\right]+\lambda_{2}\left(\sum_{y=1}^{\infty} y \frac{1}{b_{2}-a_{2}+1}\right) \frac{1}{\theta}
\end{aligned}
$$




\section{PERFORMANCE ANALYSIS OF THE PROPOSED COMMUNICATION NETWORK}

The performance of the proposed network is analyzed through numerical illustration. A set of values of the input parameters are considered for allocation of bandwidth and arrival of packets. After interacting with the internet service provider, it is considered that the message arrival rate $\left(\lambda_{1}\right)$ varies from $0.5 \times 10^{4}$ messages $/ \mathrm{sec}$ to $2 \times 10^{4}$ messages $/ \mathrm{sec}$ and the message arrival rate $\left(\lambda_{2}\right)$ varies from $1 \times 10^{4}$ messages $/ \mathrm{sec}$ to $2.5 \times 10^{4}$ messages/sec. The number of packets that can be converted from a message varies from 1 to 14 . The message arrivals to the buffer are in batches of random size. The batch size is assumed to follow uniform distribution parameters (a1, b1, a2, b2). The transmission rate of node $1(\beta)$ varies from $6 \times 10^{4}$ packets $/ \mathrm{sec}$ to $9 \times 10^{4}$ packets/sec. The packets leave the second node with a transmission rate $(\delta)$ which varies from $11 \times 10^{4}$ packets $/ \mathrm{sec}$ to $14 \times 10^{4}$ packets/sec. The packets leave the third node with a transmission rate $(\theta)$ which varies from $16 \times 10^{4}$ packets/sec to $19 \times 10^{4}$ packets $/ \mathrm{sec}$. In all the three nodes, dynamic bandwidth allocation is considered i.e. the transmission rate of each packet depends on the number of packets in the buffer connected to it at that instant. The probability of network emptiness and different buffers emptiness are computed for different values of a1, b1, a2, b2, $\lambda 1, \lambda 2, \beta, \delta, \theta$. It is observed that the probability of emptiness of the communication network and the three buffers are highly sensitive. When the batch distribution parameter (a1) varies from $2 \times 10^{4}$ packets/sec to $5 \times 10^{4}$ packets/sec, the probability of emptiness of the network decreases from 0.734 to 0.068 when other parameters are fixed at $(5,2,10,1,2,5,10,15)$ for (b1, a2, b2, $\lambda 1, \lambda 2, \beta, \delta, \theta$.). The same phenomenon is observed with respect to the first, second and third nodes. The probability of emptiness of the first, second and third buffers decrease from 0.882 to 0.176 and 0.876 to 0.242 and 0.926 to 0.389 respectively.

When the batch size distribution parameter (b1) varies from $6 \times 10^{4}$ packets $/ \mathrm{sec}$ to $9 \times 10^{4}$ packets $/ \mathrm{sec}$, the probability of emptiness of the network decreases from 0.494 to 0.464 when other parameters are fixed at $(1,2,10,1,2,5,10,15)$ for (a1, $\mathrm{a} 2, \mathrm{~b} 2, \lambda 1, \lambda 2, \beta, \delta, \theta$.). The same phenomenon is observed with respect to the first, second and third node. The probability of emptiness of the first, second and third buffers decrease from 0.978 to $0.967,0.933$ to 0.928 and 0.966 to 0.962 respectively. When the batch distribution parameter (a2) varies from $3 \times 10^{4}$ packets/sec to $6 \times 10^{4}$ packets $/ \mathrm{sec}$, the probability of emptiness of the network decreases from 0.872 to 0.534 when other parameters are fixed at $(1,5,10,1,2,5$,
$10,15)$ for $(a 1, b 1, b 2, \lambda 1, \lambda 2, \beta, \delta, \theta$.). The same phenomenon is observed with respect to the first, second and third nodes. The probability of emptiness of the first is constant, second and third buffers decrease from 0.872 to 0.534 and 0.943 to 0.849 respectively. When the batch size distribution parameter (b2) varies from $11 \times 10^{4}$ packets/sec to $14 \times 10^{4}$ packets/sec, the probability of emptiness of the network decreases from 0.384 to 0.262 when other parameters are fixed at $(1,5,2,1,2,5,10,15)$ for $(\mathrm{a} 1, \mathrm{a} 2, \mathrm{~b} 1$, $\lambda 1, \lambda 2, \beta, \delta, \theta$.). The same phenomenon is observed with respect to the first, second and third node. The probability of emptiness of the first is constant, second and third buffers decrease from 0.942 to 0.930 , and 0.968 to 0.963 respectively. The influence of arrival of messages on system emptiness is also studied. As the arrival rate $(\lambda 1)$ varies from $0.5 \times 10^{4}$ messages/sec to $2 \times 10^{4}$ messages/sec, the probability of emptiness of the network decreases from 0.910 to 0.203 when other parameters are fixed at $(1,5,2,10,2,5,10,15)$ for $(\mathrm{a} 1, \mathrm{a} 2, \mathrm{~b} 1, \mathrm{~b} 2, \lambda 2, \beta, \delta, \theta)$. The same phenomenon is observed with respect to the first second and third nodes. The probability of emptiness of the first, the second and third buffer decrease from 0.980 to $0.923,0.934$ to 0.905 and 0.967 to 0.947 respectively. As the arrival rate $(\lambda 2)$ varies from $1 \times 10^{4}$ messages $/ \mathrm{sec}$ to $2.5 \times 10^{4}$ messages $/ \mathrm{sec}$, the probability of emptiness of the network decreases from 0.615 to 0.159 when other parameters are fixed at $(1,5,2,10,1,5,10,15)$ for $(\mathrm{a} 1, \mathrm{a} 2, \mathrm{~b} 1, \mathrm{~b} 2, \lambda 1, \beta, \delta, \theta)$. The same phenomenon is observed with respect to the first second and third nodes. The probability of emptiness of the first is constant, the second and third buffer decrease from 0.952 to 0.911 , and 0.973 to 0.953 respectively. When the transmission rate $(\beta)$ of node 1 varies from $6 \times 10^{4}$ packets/sec to $9 \times 10^{4}$ packets/sec, the probability of emptiness of the network decrease from 0.472 to 0.456 , first is decreases from 0.978 to 0.967 , and second, third nodes are constant. When other parameters remain fixed at $(1,5,2,10$, $1,2,10,15)$ for $(\mathrm{a} 1, \mathrm{a} 2, \mathrm{~b} 1, \mathrm{~b} 2, \lambda 1, \lambda 2, \delta, \theta)$. When the transmission rate of node $2(\delta)$ varies from $11 \times 10^{4}$ packets $/ \mathrm{sec}$ to $14 \times 10^{4}$ packets/sec, the probability of emptiness of the network decreases from 0.415 to 0.351 , the first, third buffer is constant, and second buffer decreases from 0.946 to 0.931 when other parameters remain fixed at $(1,5,2,10,1,2,5,15)$ for $(\mathrm{a} 1, \mathrm{a} 2, \mathrm{~b} 1, \mathrm{~b} 2, \lambda 1, \lambda 2, \beta, \theta)$. When the transmission rate of node $3(\theta)$ varies from $16 \times 10^{4}$ packets $/ \mathrm{sec}$ to $19 \times 10^{4}$ packets/sec, the probability of emptiness of the network decreases from 0.430 to 0.393 and first, second is constant and third buffer decreases from 0.968 to 0.960 . When other parameters remain fixed at $(1,5,2,10,1,2,5,10)$ for $(\mathrm{a} 1, \mathrm{a} 2$, $\mathrm{b} 1, \mathrm{~b} 2, \lambda 1, \lambda 2, \beta, \delta)$. The mean number of packets and the utilization of the network are computed for different values of a1, a2, b1, b2, $\lambda 1, \lambda 2, \beta, \delta, \theta$.

Table 1. Values of probability of emptiness mean number packets, throughputs and mean delays are in the three buffers

\begin{tabular}{|c|c|c|c|c|c|c|c|c|c|c|c|c|c|c|c|c|c|c|c|c|c|c|c|c|c|}
\hline 11 & b1 & a2 & b2 & $\begin{array}{l}\lambda 1 \\
\#\end{array}$ & $\begin{array}{l}\lambda 2 \\
\#\end{array}$ & $\beta^{\$}$ & $\delta^{\$}$ & $\theta^{\$}$ & $\mathbf{p}$ & P1 & P2 & P3 & $\mathbf{L}_{1}$ & $\mathbf{L}_{2}$ & $\mathbf{L}_{3}$ & Ln & $\mathbf{U}_{1}$ & $\mathbf{U}_{2}$ & $\mathrm{U}_{3}$ & $\begin{array}{c}\text { Thp } \\
1\end{array}$ & $\begin{array}{c}\text { Thp } \\
2\end{array}$ & $\begin{array}{c}\text { Thp } \\
3\end{array}$ & $\mathrm{w}_{1}$ & $\mathrm{~W}_{2}$ & $\mathrm{~W}_{3}$ \\
\hline 2 & 5 & 2 & 1 & 1 & 2 & 5 & 1 & 1 & 0.73 & 0.88 & 0.87 & 0.92 & 0.15 & 0.14 & 0.09 & & 0.11 & 0.12 & 0.07 & & & & 0.25 & 0.11 & $\overline{0.08}$ \\
\hline & & & 0 & & & & 0 & 5 & & & & & & & 4 & 0.386 & & & 4 & 0.59 & 1.24 & 1.11 & 4 & 5 & 2 \\
\hline 3 & 5 & 2 & 1 & 1 & 2 & 5 & 1 & 1 & $\overline{0.21}$ & 0.74 & 0.78 & 0.85 & 0.40 & 0.26 & 0.17 & 0.84 & 0.25 & 0.21 & 0.14 & 1.25 & & & 0.31 & 0.12 & 0.08 \\
\hline & & & & & & & 0 & 5 & & & & & & & & & & 9 & 4 & & 2.19 & 2.16 & 9 & 2 & 5 \\
\hline 4 & 5 & 2 & 1 & 1 & 2 & 5 & 1 & 1 & .11 & 0.52 & 0.59 & .71 & & 0.56 & 0.37 & 1.94 & 0.47 & 0.40 & 0.28 & & & 30 & 0.42 & .14 & 0.08 \\
\hline 4 & & & & & & & & 5 & & & & & & 0.50 & & 1.07 & & & & 2.37 & & 30 & +2 & $\begin{array}{r}1.4 \\
\end{array}$ & 8 \\
\hline 5 & 5 & 2 & 1 & 1 & 2 & 5 & 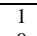 & 1 & & & $\overline{0 .}$ & & & 1.5 & & 5.61 & 0.82 & 0.75 & $\overline{0.61}$ & & & 9.16 & $\overline{0.72}$ & 0.20 & 0.11 \\
\hline 1 & 6 & 2 & $\frac{0}{1}$ & 1 & 2 & 5 & $\frac{0}{1}$ & & & & & & & & & $\begin{array}{l}1 \\
0.15\end{array}$ & 02 & & & & & & 20 & $\frac{7}{0.11}$ & \begin{tabular}{|l|l}
0.10 \\
\end{tabular} \\
\hline & & & 0 & & & & 0 & 5 & & & & & & & & & & & 4 & & & & $\begin{array}{r}0 \\
0\end{array}$ & $\begin{array}{r}1 \\
6\end{array}$ & $\begin{array}{c}.110 \\
2\end{array}$ \\
\hline 1 & 7 & 2 & 1 & 1 & 2 & 5 & 1 & 1 & 0.48 & 0.97 & 0.9 & 0.96 & 0.0 & 0.07 & 0.05 & 0.15 & 0.02 & 0.06 & 0.03 & 0.12 & & 0.52 & 0.20 & 0.11 & 0.10 \\
\hline & & & 0 & & & & 0 & 5 & & & & & & & & & & & & & .68 & & 0 & 6 & \\
\hline 1 & 8 & 2 & 1 & 1 & 2 & 5 & 1 & 1 & 0.4 & 0.97 & $\overline{0.93}$ & 0.9 & $\overline{0 .}$ & 0.08 & 0.0 & 0.16 & 0.02 & & 0.03 & & & & 0.20 & 0.11 & $\overline{0.10}$ \\
\hline & & & & & & & 0 & 5 & & & & & & & & 4 & & 07 & 6 & & & 0.54 & 0 & 6 & 0 \\
\hline 1 & 9 & 2 & 1 & 1 & 2 & 5 & 1 & & & & & & & 0.08 & 0.0 & 0.17 & 0.03 & 0.07 & 0.03 & & & & 0.20 & 0.11 & 0.09 \\
\hline & & & 1 & & & & 0 & 5 & & & & & & 0.00 & & 0.11 & 0.05 & $\begin{array}{r}01 \\
\end{array}$ & $\begin{array}{r}0.03 \\
\end{array}$ & & & .57 & $\begin{array}{r}-.20 \\
\end{array}$ & $\begin{array}{r}11 \\
\end{array}$ & 8 \\
\hline 1 & 5 & 3 & 1 & 1 & 2 & 5 & 1 & 1 & & 0.96 & 0.87 & 0. & 0.0 & 0.1 & 0.11 & 0.32 & 0.03 & 0.12 & 0.05 & 1.19 & & 0.85 & 0.20 & 0.67 & 0.13 \\
\hline 1 & 5 & 4 & $\frac{0}{1}$ & 1 & 2 & 5 & $\frac{0}{1}$ & 5 & & $\frac{1}{0.96}$ & $\frac{2}{079}$ & $\frac{3}{09}$ & & & 3 & & $\begin{array}{r}9 \\
0.9\end{array}$ & 20 & & $\frac{19}{19}$ & & & $\begin{array}{r}5 \\
020\end{array}$ & $\frac{2}{25}$ & $\frac{2}{017}$ \\
\hline & & 4 & 0 & & 2 & & 0 & 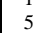 & & 0.9 & 0.7 & 0 & & & $\begin{array}{c}0.26 \\
4\end{array}$ & 55 & 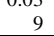 & 3 & 0.08 & $\begin{array}{r}19 \\
5\end{array}$ & & 1.2 & $\begin{array}{r}0 \\
5\end{array}$ & 6 & 0 \\
\hline & 5 & 5 & 1 & 1 & $\overline{2}$ & 5 & 1 & 1 & 0.77 & 0.96 & 0.69 & 0.89 & 0.04 & 0.52 & 0.34 & 0.90 & 0.03 & 0.31 & 0.10 & 0.19 & 3.1 & 1.63 & 0.20 & 0.09 & 0.21 \\
\hline
\end{tabular}




\begin{tabular}{|c|c|c|c|c|c|c|c|c|c|c|c|c|c|c|c|c|c|c|c|c|c|c|c|c|c|}
\hline & & & 0 & & & & 0 & 5 & 7 & 1 & 0 & 1 & 0 & 0 & 7 & 7 & 9 & & 9 & 5 & & 5 & 5 & 9 & 2 \\
\hline 1 & 5 & 6 & $\begin{array}{l}1 \\
0\end{array}$ & 1 & 2 & 5 & $\begin{array}{l}1 \\
0\end{array}$ & $\begin{array}{l}1 \\
5\end{array}$ & $\begin{array}{c}0.41 \\
6\end{array}$ & $\begin{array}{c}0.96 \\
1\end{array}$ & $\begin{array}{c}0.53 \\
4\end{array}$ & $\begin{array}{c}0.84 \\
9\end{array}$ & $\begin{array}{c}0.04 \\
0\end{array}$ & $\begin{array}{c}0.86 \\
0\end{array}$ & $\begin{array}{c}0.57 \\
3\end{array}$ & $\begin{array}{c}1.47 \\
3\end{array}$ & $\begin{array}{r}0.03 \\
9\end{array}$ & $\begin{array}{r}0.46 \\
6\end{array}$ & $\begin{array}{r}0.15 \\
1\end{array}$ & $\begin{array}{r}0.19 \\
5\end{array}$ & 4.66 & $\begin{array}{c}2.26 \\
5\end{array}$ & $\begin{array}{r}0.20 \\
5\end{array}$ & $\begin{array}{r}0.03 \\
6\end{array}$ & $\begin{array}{c}0.25 \\
3\end{array}$ \\
\hline 1 & 5 & 2 & $\begin{array}{l}1 \\
1\end{array}$ & 1 & 2 & 5 & $\begin{array}{l}1 \\
0\end{array}$ & $\begin{array}{l}1 \\
5\end{array}$ & $\begin{array}{c}0.38 \\
4\end{array}$ & $\begin{array}{c}0.96 \\
1\end{array}$ & $\begin{array}{c}0.94 \\
2\end{array}$ & $\begin{array}{c}0.96 \\
8\end{array}$ & $\begin{array}{c}0.04 \\
0\end{array}$ & $\begin{array}{c}0.06 \\
6\end{array}$ & $\begin{array}{c}0.04 \\
4\end{array}$ & 0.15 & $\begin{array}{r}0.03 \\
9\end{array}$ & $\begin{array}{r}0.05 \\
8\end{array}$ & $\begin{array}{r}0.03 \\
2\end{array}$ & $\begin{array}{r}0.19 \\
5\end{array}$ & 0.58 & 0.48 & $\begin{array}{r}0.20 \\
5\end{array}$ & $\begin{array}{r}0.11 \\
4\end{array}$ & $\begin{array}{c}0.09 \\
5\end{array}$ \\
\hline 1 & 5 & 2 & $\begin{array}{l}1 \\
2\end{array}$ & 1 & 2 & 5 & $\begin{array}{l}1 \\
0\end{array}$ & $\begin{array}{l}1 \\
5\end{array}$ & $\begin{array}{c}0.33 \\
4\end{array}$ & $\begin{array}{c}0.96 \\
1\end{array}$ & $\begin{array}{c}0.93 \\
9\end{array}$ & $\begin{array}{c}0.96 \\
7\end{array}$ & $\begin{array}{c}0.04 \\
0\end{array}$ & $\begin{array}{c}0.07 \\
0\end{array}$ & $\begin{array}{c}0.04 \\
7\end{array}$ & $\begin{array}{c}0.15 \\
7\end{array}$ & $\begin{array}{r}0.03 \\
9\end{array}$ & $\begin{array}{r}0.06 \\
1\end{array}$ & $\begin{array}{r}0.03 \\
3\end{array}$ & $\begin{array}{r}0.19 \\
5\end{array}$ & 0.61 & $\begin{array}{c}0.49 \\
5\end{array}$ & \begin{tabular}{|r}
0.20 \\
5
\end{tabular} & $\begin{array}{r}0.11 \\
4\end{array}$ & $\begin{array}{c}0.09 \\
5\end{array}$ \\
\hline 1 & 5 & 2 & $\begin{array}{l}1 \\
3\end{array}$ & 1 & 2 & 5 & $\begin{array}{l}1 \\
0\end{array}$ & $\begin{array}{l}1 \\
5\end{array}$ & $\begin{array}{c}0.29 \\
5\end{array}$ & $\begin{array}{c}0.96 \\
1\end{array}$ & $\begin{array}{c}0.93 \\
5\end{array}$ & $\begin{array}{c}0.96 \\
5\end{array}$ & $\begin{array}{c}0.04 \\
0\end{array}$ & $\begin{array}{c}0.07 \\
5\end{array}$ & $\begin{array}{c}0.05 \\
0\end{array}$ & $\begin{array}{c}0.16 \\
5\end{array}$ & $\begin{array}{r}0.03 \\
9 \\
\end{array}$ & $\begin{array}{r}0.06 \\
5\end{array}$ & $\begin{array}{r}0.03 \\
5\end{array}$ & $\begin{array}{r}0.19 \\
5 \\
\end{array}$ & 0.65 & $\begin{array}{c}0.52 \\
5\end{array}$ & $\begin{array}{r}0.20 \\
5\end{array}$ & $\begin{array}{r}0.11 \\
4 \\
\end{array}$ & $\begin{array}{c}0.09 \\
5\end{array}$ \\
\hline 1 & 5 & 2 & $\begin{array}{l}1 \\
4 \\
\end{array}$ & 1 & 2 & 5 & $\begin{array}{l}1 \\
0\end{array}$ & $\begin{array}{l}1 \\
5\end{array}$ & $\begin{array}{c}0.26 \\
2\end{array}$ & $\begin{array}{c}0.96 \\
1\end{array}$ & $\begin{array}{c}0.93 \\
0\end{array}$ & $\begin{array}{c}0.96 \\
3\end{array}$ & $\begin{array}{c}0.04 \\
0\end{array}$ & $\begin{array}{c}0.08 \\
0\end{array}$ & $\begin{array}{c}0.05 \\
3\end{array}$ & $\begin{array}{c}0.17 \\
3 \\
\end{array}$ & $\begin{array}{r}0.03 \\
9 \\
\end{array}$ & 0.07 & $\begin{array}{r}0.03 \\
7 \\
\end{array}$ & $\begin{array}{r}0.19 \\
5 \\
\end{array}$ & 0.7 & $\begin{array}{c}0.55 \\
5\end{array}$ & $\begin{array}{r}0.20 \\
5\end{array}$ & $\begin{array}{r}0.11 \\
4 \\
\end{array}$ & $\begin{array}{c}0.09 \\
5\end{array}$ \\
\hline 1 & 5 & 2 & $\begin{array}{l}1 \\
0\end{array}$ & 1 & 2 & 5 & $\begin{array}{l}1 \\
0\end{array}$ & $\begin{array}{l}1 \\
5\end{array}$ & $\begin{array}{c}0.73 \\
9\end{array}$ & $\begin{array}{c}0.96 \\
1\end{array}$ & $\begin{array}{c}0.92 \\
5\end{array}$ & $\begin{array}{c}0.96 \\
0\end{array}$ & $\begin{array}{c}0.04 \\
0\end{array}$ & $\begin{array}{c}0.08 \\
7\end{array}$ & $\begin{array}{c}0.05 \\
8\end{array}$ & \begin{tabular}{c|}
0.18 \\
5
\end{tabular} & $\begin{array}{r}0.03 \\
9\end{array}$ & $\begin{array}{r}0.07 \\
5\end{array}$ & 0.0 & $\begin{array}{r}0.19 \\
5\end{array}$ & 0.75 & 0.6 & $\begin{array}{r}0.20 \\
5\end{array}$ & $\begin{array}{r}0.11 \\
6\end{array}$ & $\begin{array}{c}0.09 \\
7\end{array}$ \\
\hline 1 & 5 & 2 & $\begin{array}{l}1 \\
0\end{array}$ & 1.5 & 2 & 5 & $\begin{array}{l}1 \\
0\end{array}$ & $\begin{array}{l}1 \\
5\end{array}$ & $\begin{array}{c}0.44 \\
6\end{array}$ & $\begin{array}{c}0.94 \\
2\end{array}$ & $\begin{array}{c}0.91 \\
5\end{array}$ & $\begin{array}{c}0.95 \\
4\end{array}$ & $\begin{array}{c}0.06 \\
0\end{array}$ & $\begin{array}{c}0.09 \\
7\end{array}$ & $\begin{array}{c}0.06 \\
4\end{array}$ & $\begin{array}{c}0.22 \\
1\end{array}$ & $\begin{array}{r}0.05 \\
8\end{array}$ & $\begin{array}{r}0.08 \\
5\end{array}$ & $\begin{array}{r}0.04 \\
6\end{array}$ & 0.29 & 0.85 & 0.69 & $\begin{array}{r}0.20 \\
7\end{array}$ & $\begin{array}{r}0.11 \\
4\end{array}$ & $\begin{array}{c}0.09 \\
3\end{array}$ \\
\hline 1 & 5 & 2 & $\begin{array}{l}1 \\
0 \\
\end{array}$ & 2 & 2 & 5 & $\begin{array}{l}1 \\
0 \\
\end{array}$ & $\begin{array}{l}1 \\
5 \\
\end{array}$ & $\begin{array}{c}0.20 \\
3\end{array}$ & $\begin{array}{c}0.92 \\
3\end{array}$ & $\begin{array}{c}0.90 \\
5\end{array}$ & $\begin{array}{c}0.94 \\
7\end{array}$ & $\begin{array}{c}0.08 \\
0\end{array}$ & $\begin{array}{c}0.10 \\
7\end{array}$ & $\begin{array}{c}0.07 \\
1\end{array}$ & \begin{tabular}{c|}
0.25 \\
8
\end{tabular} & $\begin{array}{r}0.07 \\
7\end{array}$ & $\begin{array}{r}0.09 \\
5\end{array}$ & $\begin{array}{r}0.05 \\
3\end{array}$ & $\begin{array}{r}0.38 \\
5\end{array}$ & 0.95 & $\begin{array}{c}0.79 \\
5\end{array}$ & $\begin{array}{r}0.20 \\
8\end{array}$ & $\begin{array}{r}0.11 \\
3\end{array}$ & $\begin{array}{c}0.08 \\
9\end{array}$ \\
\hline 1 & 5 & 2 & $\begin{array}{l}1 \\
0\end{array}$ & 1 & 1 & 5 & $\begin{array}{l}1 \\
0\end{array}$ & $\begin{array}{l}1 \\
5\end{array}$ & $\begin{array}{c}0.61 \\
5\end{array}$ & $\begin{array}{c}0.96 \\
1\end{array}$ & $\begin{array}{c}0.95 \\
2\end{array}$ & $\begin{array}{c}0.97 \\
3\end{array}$ & $\begin{array}{c}0.04 \\
0\end{array}$ & $\begin{array}{c}0.05 \\
3\end{array}$ & $\begin{array}{c}0.03 \\
6\end{array}$ & $\begin{array}{c}0.12 \\
9\end{array}$ & $\begin{array}{r}0.03 \\
9\end{array}$ & $\begin{array}{r}0.04 \\
8\end{array}$ & $\begin{array}{r}0.02 \\
7\end{array}$ & $\begin{array}{r}0.19 \\
5\end{array}$ & 0.48 & $\begin{array}{c}0.40 \\
5\end{array}$ & $\begin{array}{r}0.20 \\
5\end{array}$ & $\begin{array}{r}0.11 \\
0\end{array}$ & $\begin{array}{c}0.08 \\
9\end{array}$ \\
\hline 1 & 5 & 2 & $\begin{array}{l}1 \\
0\end{array}$ & 1 & 1.5 & 5 & $\begin{array}{l}1 \\
0\end{array}$ & $\begin{array}{l}1 \\
5\end{array}$ & $\begin{array}{l}0.44 \\
0\end{array}$ & $\begin{array}{l}0.96 \\
1\end{array}$ & $\begin{array}{l}0.93 \\
9\end{array}$ & $\begin{array}{l}0.96 \\
7\end{array}$ & $\begin{array}{l}0.04 \\
0\end{array}$ & $\begin{array}{l}0.07 \\
0\end{array}$ & $\begin{array}{l}0.04 \\
7\end{array}$ & \begin{tabular}{l|}
0.15 \\
7
\end{tabular} & $\begin{array}{l}0.03 \\
9\end{array}$ & $\begin{array}{l}0.06 \\
1\end{array}$ & $\begin{array}{l}0.03 \\
3\end{array}$ & $\begin{array}{l}0.19 \\
5\end{array}$ & 0.61 & $\begin{array}{c}0.49 \\
5\end{array}$ & $\begin{array}{l}0.20 \\
5\end{array}$ & $\begin{array}{l}0.11 \\
5\end{array}$ & $\begin{array}{c}0.09 \\
5\end{array}$ \\
\hline 1 & 5 & 2 & $\begin{array}{l}1 \\
0\end{array}$ & 1 & 2.5 & 5 & $\begin{array}{l}1 \\
0\end{array}$ & $\begin{array}{l}1 \\
5\end{array}$ & $\begin{array}{l}0.15 \\
9\end{array}$ & $\begin{array}{l}0.96 \\
1\end{array}$ & $\begin{array}{l}0.91 \\
1\end{array}$ & $\begin{array}{l}0.95 \\
3\end{array}$ & $\begin{array}{l}0.04 \\
0\end{array}$ & $\begin{array}{l}0.10 \\
3\end{array}$ & $\begin{array}{l}0.06 \\
9\end{array}$ & \begin{tabular}{l|}
0.21 \\
2
\end{tabular} & $\begin{array}{l}0.03 \\
9\end{array}$ & $\begin{array}{l}0.08 \\
9\end{array}$ & $\begin{array}{l}0.04 \\
7\end{array}$ & $\begin{array}{l}0.19 \\
5\end{array}$ & 0.89 & $\begin{array}{c}0.70 \\
5\end{array}$ & $\begin{array}{l}0.20 \\
5\end{array}$ & $\begin{array}{l}0.11 \\
7 \\
\end{array}$ & $\begin{array}{c}0.09 \\
8\end{array}$ \\
\hline 1 & 5 & 2 & $\begin{array}{l}1 \\
0\end{array}$ & 1 & 2 & 6 & $\begin{array}{l}1 \\
0\end{array}$ & $\begin{array}{l}1 \\
5 \\
\end{array}$ & $\begin{array}{c}0.47 \\
2\end{array}$ & $\begin{array}{c}0.97 \\
8\end{array}$ & $\begin{array}{c}0.92 \\
5\end{array}$ & $\begin{array}{c}0.96 \\
0\end{array}$ & $\begin{array}{c}0.02 \\
2\end{array}$ & $\begin{array}{c}0.08 \\
7\end{array}$ & $\begin{array}{c}0.05 \\
8\end{array}$ & $\begin{array}{c}0.16 \\
7\end{array}$ & $\begin{array}{r}0.02 \\
2 \\
\end{array}$ & $\begin{array}{r}0.07 \\
5 \\
\end{array}$ & 0.04 & $\begin{array}{r}0.13 \\
2 \\
\end{array}$ & 0.75 & 0.6 & $\begin{array}{r}0.16 \\
7 \\
\end{array}$ & $\begin{array}{r}0.11 \\
6 \\
\end{array}$ & $\begin{array}{c}0.09 \\
7\end{array}$ \\
\hline 1 & 5 & 2 & $\begin{array}{l}1 \\
0\end{array}$ & 1 & 2 & 7 & $\begin{array}{l}1 \\
0\end{array}$ & $\begin{array}{l}1 \\
5\end{array}$ & $\begin{array}{c}0.46 \\
8\end{array}$ & $\begin{array}{c}0.97 \\
5\end{array}$ & $\begin{array}{c}0.92 \\
5\end{array}$ & $\begin{array}{c}0.96 \\
0\end{array}$ & $\begin{array}{c}0.02 \\
5\end{array}$ & $\begin{array}{c}0.08 \\
7\end{array}$ & $\begin{array}{c}0.05 \\
8\end{array}$ & 0.17 & $\begin{array}{r}0.02 \\
5\end{array}$ & $\begin{array}{r}0.07 \\
5\end{array}$ & 0.04 & $\begin{array}{r}0.17 \\
5\end{array}$ & 0.75 & 0.6 & \begin{tabular}{|r}
0.14 \\
3
\end{tabular} & $\begin{array}{r}0.11 \\
6\end{array}$ & $\begin{array}{c}0.09 \\
7\end{array}$ \\
\hline 1 & 5 & 2 & $\begin{array}{l}1 \\
0\end{array}$ & 1 & 2 & 8 & $\begin{array}{l}1 \\
0\end{array}$ & $\begin{array}{l}1 \\
5\end{array}$ & $\begin{array}{c}0.46 \\
3\end{array}$ & $\begin{array}{c}0.97 \\
2\end{array}$ & $\begin{array}{c}0.92 \\
5\end{array}$ & $\begin{array}{c}0.96 \\
0\end{array}$ & $\begin{array}{c}0.02 \\
9\end{array}$ & $\begin{array}{c}0.08 \\
7\end{array}$ & $\begin{array}{c}0.05 \\
8\end{array}$ & $\begin{array}{c}0.17 \\
4\end{array}$ & $\begin{array}{r}0.02 \\
8\end{array}$ & $\begin{array}{r}0.07 \\
5\end{array}$ & 0.04 & $\begin{array}{r}0.22 \\
4\end{array}$ & 0.75 & 0.6 & $\begin{array}{r}0.12 \\
9\end{array}$ & $\begin{array}{r}0.11 \\
6\end{array}$ & $\begin{array}{c}0.09 \\
7\end{array}$ \\
\hline 1 & 5 & 2 & $\begin{array}{l}1 \\
0\end{array}$ & 1 & 2 & 9 & $\begin{array}{l}1 \\
0\end{array}$ & $\begin{array}{l}1 \\
5\end{array}$ & $\begin{array}{c}0.45 \\
6\end{array}$ & $\begin{array}{c}0.96 \\
7\end{array}$ & $\begin{array}{c}0.92 \\
5\end{array}$ & $\begin{array}{c}0.96 \\
0\end{array}$ & $\begin{array}{c}0.03 \\
3\end{array}$ & $\begin{array}{c}0.08 \\
7\end{array}$ & $\begin{array}{c}0.05 \\
8\end{array}$ & \begin{tabular}{|c|}
0.17 \\
8
\end{tabular} & $\begin{array}{r}0.03 \\
3\end{array}$ & $\begin{array}{r}0.07 \\
5\end{array}$ & 0.04 & $\begin{array}{r}0.29 \\
7\end{array}$ & 0.75 & 0.6 & $\begin{array}{r}0.11 \\
1\end{array}$ & $\begin{array}{r}0.11 \\
6\end{array}$ & $\begin{array}{c}0.09 \\
7\end{array}$ \\
\hline$\overline{1}$ & 5 & 2 & $\begin{array}{l}0 \\
0 \\
0\end{array}$ & 1 & 2 & 5 & $\begin{array}{l}1 \\
1\end{array}$ & $\begin{array}{l}1 \\
5\end{array}$ & $\begin{array}{c}0.41 \\
5\end{array}$ & $\begin{array}{c}0.96 \\
1\end{array}$ & $\begin{array}{c}0.94 \\
6\end{array}$ & $\begin{array}{c}0.96 \\
0\end{array}$ & $\begin{array}{c}0.04 \\
0\end{array}$ & $\begin{array}{c}1 \\
0.06 \\
2\end{array}$ & $\begin{array}{c}0.05 \\
8\end{array}$ & 0.16 & $\begin{array}{r}0.03 \\
9 \\
\end{array}$ & $\begin{array}{r}0.05 \\
4\end{array}$ & 0.04 & $\begin{array}{r}19 \\
0.19 \\
\end{array}$ & $\begin{array}{l}0.59 \\
4\end{array}$ & 0.6 & $\begin{array}{r}1 \\
0.20 \\
5\end{array}$ & $\begin{array}{r}0.10 \\
4\end{array}$ & $\begin{array}{c}1 \\
0.09 \\
7\end{array}$ \\
\hline 1 & 5 & 2 & $\begin{array}{l}1 \\
0\end{array}$ & 1 & 2 & 5 & $\begin{array}{l}1 \\
2\end{array}$ & $\begin{array}{l}1 \\
5\end{array}$ & $\begin{array}{c}0.39 \\
0\end{array}$ & $\begin{array}{c}0.96 \\
1\end{array}$ & $\begin{array}{c}0.94 \\
2\end{array}$ & $\begin{array}{c}0.96 \\
0\end{array}$ & $\begin{array}{c}0.04 \\
0\end{array}$ & $\begin{array}{c}0.06 \\
7\end{array}$ & $\begin{array}{c}0.05 \\
8\end{array}$ & $\begin{array}{c}0.16 \\
5\end{array}$ & $\begin{array}{r}0.03 \\
9\end{array}$ & $\begin{array}{r}0.05 \\
8\end{array}$ & 0.04 & $\begin{array}{r}0.19 \\
5\end{array}$ & $\begin{array}{l}0.69 \\
6\end{array}$ & 0.6 & $\begin{array}{r}0.20 \\
5\end{array}$ & $\begin{array}{r}0.09 \\
6\end{array}$ & $\begin{array}{c}0.09 \\
7\end{array}$ \\
\hline 1 & 5 & 2 & $\begin{array}{l}1 \\
0\end{array}$ & 1 & 2 & 5 & $\begin{array}{l}1 \\
3\end{array}$ & $\begin{array}{l}1 \\
5\end{array}$ & $\begin{array}{c}0.36 \\
9\end{array}$ & $\begin{array}{c}0.96 \\
1\end{array}$ & $\begin{array}{c}0.93 \\
7\end{array}$ & $\begin{array}{c}0.96 \\
0\end{array}$ & $\begin{array}{c}0.04 \\
0\end{array}$ & $\begin{array}{c}0.07 \\
2\end{array}$ & $\begin{array}{c}0.05 \\
8\end{array}$ & 0.17 & $\begin{array}{r}0.03 \\
9 \\
\end{array}$ & $\begin{array}{r}0.06 \\
3 \\
\end{array}$ & 0.04 & $\begin{array}{r}0.19 \\
5 \\
\end{array}$ & $\begin{array}{l}0.81 \\
9\end{array}$ & 0.6 & $\begin{array}{r}0.20 \\
5 \\
\end{array}$ & $\begin{array}{r}0.08 \\
8\end{array}$ & $\begin{array}{c}0.09 \\
7\end{array}$ \\
\hline 1 & 5 & 2 & $\begin{array}{l}1 \\
0\end{array}$ & 1 & 2 & 5 & $\begin{array}{l}1 \\
4\end{array}$ & $\begin{array}{l}1 \\
5\end{array}$ & $\begin{array}{c}0.35 \\
1\end{array}$ & $\begin{array}{c}0.96 \\
1\end{array}$ & $\begin{array}{c}0.93 \\
1\end{array}$ & $\begin{array}{c}0.96 \\
0\end{array}$ & $\begin{array}{c}0.04 \\
0\end{array}$ & $\begin{array}{c}0.07 \\
9\end{array}$ & $\begin{array}{c}0.05 \\
8\end{array}$ & $\begin{array}{c}0.17 \\
7\end{array}$ & $\begin{array}{r}0.03 \\
9\end{array}$ & $\begin{array}{r}0.06 \\
9\end{array}$ & 0.04 & $\begin{array}{r}0.19 \\
5\end{array}$ & $\begin{array}{l}0.96 \\
6\end{array}$ & 0.6 & $\begin{array}{r}0.20 \\
5\end{array}$ & $\begin{array}{r}0.08 \\
2\end{array}$ & $\begin{array}{c}0.09 \\
7\end{array}$ \\
\hline 1 & 5 & 2 & $\begin{array}{l}1 \\
0\end{array}$ & 1 & 2 & 5 & $\begin{array}{l}1 \\
0\end{array}$ & $\begin{array}{l}1 \\
6\end{array}$ & $\begin{array}{c}0.43 \\
0\end{array}$ & $\begin{array}{c}0.96 \\
1\end{array}$ & $\begin{array}{c}0.92 \\
5\end{array}$ & $\begin{array}{c}0.96 \\
8\end{array}$ & $\begin{array}{c}0.04 \\
0\end{array}$ & $\begin{array}{c}0.08 \\
7\end{array}$ & $\begin{array}{c}0.04 \\
0\end{array}$ & $\begin{array}{c}0.16 \\
7\end{array}$ & $\begin{array}{r}0.03 \\
9\end{array}$ & $\begin{array}{r}0.07 \\
5\end{array}$ & $\begin{array}{r}0.03 \\
2\end{array}$ & $\begin{array}{r}0.19 \\
5\end{array}$ & 0.75 & $\begin{array}{c}0.51 \\
2\end{array}$ & $\begin{array}{r}0.20 \\
5\end{array}$ & $\begin{array}{r}0.11 \\
6\end{array}$ & $\begin{array}{c}0.07 \\
8\end{array}$ \\
\hline 1 & 5 & 2 & $\begin{array}{l}1 \\
0\end{array}$ & 1 & 2 & 5 & $\begin{array}{l}1 \\
0\end{array}$ & $\begin{array}{l}1 \\
7\end{array}$ & $\begin{array}{c}0.41 \\
7\end{array}$ & $\begin{array}{c}0.96 \\
1\end{array}$ & $\begin{array}{c}0.92 \\
5\end{array}$ & $\begin{array}{c}0.96 \\
5\end{array}$ & $\begin{array}{c}0.04 \\
0\end{array}$ & $\begin{array}{c}0.08 \\
7\end{array}$ & $\begin{array}{c}0.04 \\
8\end{array}$ & $\begin{array}{c}0.17 \\
5\end{array}$ & $\begin{array}{r}0.03 \\
9\end{array}$ & $\begin{array}{r}0.07 \\
5\end{array}$ & $\begin{array}{r}0.03 \\
5\end{array}$ & $\begin{array}{r}0.19 \\
5\end{array}$ & 0.75 & $\begin{array}{c}0.59 \\
5\end{array}$ & $\begin{array}{r}0.20 \\
5\end{array}$ & $\begin{array}{r}0.11 \\
6\end{array}$ & $\begin{array}{c}0.07 \\
6\end{array}$ \\
\hline 1 & 5 & 2 & $\begin{array}{l}1 \\
0\end{array}$ & 1 & 2 & 5 & $\begin{array}{l}1 \\
0\end{array}$ & $\begin{array}{l}1 \\
9\end{array}$ & $\begin{array}{c}0.39 \\
3\end{array}$ & $\begin{array}{c}0.96 \\
1\end{array}$ & $\begin{array}{c}0.92 \\
5\end{array}$ & $\begin{array}{c}0.96 \\
0\end{array}$ & $\begin{array}{c}0.04 \\
0\end{array}$ & $\begin{array}{c}0.08 \\
7\end{array}$ & $\begin{array}{c}0.05 \\
4\end{array}$ & $\begin{array}{c}0.18 \\
1\end{array}$ & $\begin{array}{r}0.03 \\
9\end{array}$ & $\begin{array}{r}0.07 \\
5\end{array}$ & 0.04 & $\begin{array}{r}0.19 \\
5\end{array}$ & 0.75 & 0.76 & $\begin{array}{r}0.20 \\
5\end{array}$ & $\begin{array}{r}0.11 \\
6\end{array}$ & $\begin{array}{c}0.07 \\
1\end{array}$ \\
\hline
\end{tabular}

\# =Multiples of 10,000 Messages/sec, \$= Multiples of 10,000 Packets/sec

Values of probability of emptiness in the three buffers are given in Table 1 and the relationship between emptiness probability and various parameters is shown in Figure 2. As the batch size distribution parameter (a1) varies from 2 to 5 , the first buffer, second buffer ,third buffer and the network average content increase from $0.150 \times 10^{4}$ packets to $3.0 \times 10^{4}$ packets, from $0.142 \times 10^{4}$ packets to $1.567 \times 10^{4}$ packets, from $0.094 \times 10^{4}$ packets to $1.044 \times 10^{4}$ packets, from $0.386 \times 10^{4}$ packets to $5.611 \times 10^{4}$ packets respectively when other parameters remain fixed. As the batch size distribution parameter (b1) varies from 6 to 9, the first buffer, second buffer, third buffer and the network average content increase from $0.022 \times 10^{4}$ packets to $0.033 \times 10^{4}$ packets, from $0.078 \times 10^{4}$ packets to $0.083 \times 10^{4}$ packets, from $0.052 \times 10^{4}$ packets to $0.056 \times 10^{4}$ packets, from $0.152 \times 10^{4}$ packets to $0.172 \times 10^{4}$ packets respectively when other parameters remain fixed. As the batch size distribution parameter (a2) varies from 3 to 6 , the first buffer is constant, second buffer, third buffer and the network average content increase from $0.170 \times 10^{4}$ packets to $0.860 \times 10^{4}$ packets, from $0.113 \times 10^{4}$ packets to $0.573 \times 10^{4}$ packets, and from $0.323 \times 10^{4}$ packets to $1.473 \times 10^{4}$ packets respectively when other parameters remain fixed. As the batch size distribution parameter (b2) varies from 11 to 14 , the first buffer is constant, second buffer, third buffer and the network average content increase from $0.066 \times 10^{4}$ packets to $0.080 \times 10^{4}$ packets, from $0.044 \times 10^{4}$ packets to $0.053 \times 10^{4}$ packets, and from $0.15 \times 10^{4}$ packets to $0.173 \times 10^{4}$ packets respectively when other parameters remain fixed. As the arrival rate of messages $(\lambda 1)$ varies from $0.5 \times 10^{4}$ messages $/ \mathrm{sec}$ to $2 \times 10^{4}$ messages $/ \mathrm{sec}$, the mean number of packets in the first buffer, second buffer, third buffer and in the network increase from $0.020 \times 10^{4}$ packets to $0.080 \times 10^{4}$ packets, from $0.077 \times 10^{4}$ packets to $0.107 \times 10^{4}$ packets, from $0.051 \times 10^{4}$ packets to $0.071 \times 10^{4}$ packets, from $0.148 \times 10^{4}$ packets to $0.258 \times 10^{4}$ packets respectively when other parameters remain fixed. As the arrival rate of messages $(\lambda 2)$ varies from $1 \times 10^{4}$ messages $/ \mathrm{sec}$ to $2.5 \times 10^{4}$ messages $/ \mathrm{sec}$, the mean number of packets in the first buffer is constant, second buffer, third buffer and in the network increase from $0.053 \times 10^{4}$ packets to $0.103 \times 10^{4}$ packets, from $0.036 \times 10^{4}$ packets to $0.069 \times 10^{4}$ packets, and from $0.129 \times 10^{4}$ packets to $0.212 \times 10^{4}$ packets, respectively when other parameters remain fixed. As the transmission rate of node1 ( $\beta$ ) varies from $6 \times 10^{4}$ packets/sec to $9 \times 10^{4}$ packets/sec, the first buffer and the network average content increases from $0.022 \times 10^{4}$ packets to $0.033 \times 10^{4}$ packets, $0.167 \times 10^{4}$ packets to $0.178 \times 10^{4}$ packets, the second and third buffers are constant when other parameters remain fixed. As the transmission rate of node $2(\delta)$ varies from $11 \times 10^{4}$ packets/sec to $14 \times 10^{4}$ packets/sec, the first, third buffers are constant ,the second buffer and the network average content increase from $0.062 \times 10^{4}$ packets to $0.079 \times 10^{4}$ packets and from $0.160 \times 10^{4}$ packets to $0.177 \times 10^{4}$ packets respectively when other parameters remain fixed. As the transmission rate of node $3(\theta)$ varies from $16 \times 10^{4}$ packets/sec to $19 \times 10^{4}$ packets/sec, the first, second buffers are constant, third buffer and the network average content increases from $0.040 \times 10^{4}$ packets to $0.054 \times 10^{4}$ packets , from $0.167 \times 10^{4}$ packets to $0.181 \times 10^{4}$ packets, when other parameters remain fixed. Values of mean number of packets and utilization in the three buffers are given in Table 1 and the relationship between 
mean number of packets, utilization and various parameters is shown in Figure 2. The throughput and the average delay of the network are computed for different values of a1, a2, b1, $\mathrm{b} 2, \lambda 1, \lambda 2, \beta, \delta, \theta$ and the values of mean delays and throughputs are given in Table 1 and the relationship between mean delays and throughputs and various parameters is shown in Figure 2. As the batch size distribution parameter (a1) varies from 2 to 5 the throughput of the first, second and third nodes increase from $0.59 \times 10^{4}$ packets to $4.12 \times 10^{4}$ packets, $1.24 \times 10^{4}$ packets to $7.58 \times 10^{4}$ packets, $1.11 \times 10^{4}$ packets to $9.165 \times 10^{4}$ packets respectively when other parameters remain fixed. As the batch size distribution parameter (b1) varies from 6 to 9 the throughput of the first, second and third nodes increase from $0.11 \times 10^{4}$ packets to $0.165 \times 10^{4}$ packets, $0.67 \times 10^{4}$ packets to $0.72 \times 10^{4}$ packets, $0.51 \times 10^{4}$ packets to $0.57 \times 10^{4}$ packets respectively when other parameters remain fixed. As the batch size distribution parameter (a2) varies from 3 to 6 the throughput of the first is constant, second and third node increase from $1.28 \times 10^{4}$ packets to $4.66 \times 10^{4}$ packets, $0.855 \times 10^{4}$ packets to $2.265 \times 10^{4}$ packets, respectively when other parameters remain fixed. As the batch size distribution parameter (b2) varies from 11 to 14 the throughput of the first is constant, second and third nodes increase from $0.58 \times 10^{4}$ packets to $0.7 \times 10^{4}$ packets, $0.48 \times 10^{4}$ packets to $0.55 \times 10^{4}$ packets, respectively when other parameters remain fixed. As the arrival rate $(\lambda 1)$ varies from 0.5 to 2 the throughput of the first, second and third nodes increase from $0.1 \times 10^{4}$ packets to $0.38 \times 10^{4}$ packets, $0.66 \times 10^{4}$ packets to $0.95 \times 10^{4}$ packets, $0.495 \times 10^{4}$ packets to $0.795 \times 10^{4}$ packets respectively when other parameters remain fixed. As the arrival rate $(\lambda 2)$ varies from 1 to 2.5 the throughput of the first is constant, second and third nodes increase from $0.48 \times 10^{4}$ packets to $0.89 \times 10^{4}$ packets, $0.405 \times 10^{4}$ packets to $0.705 \times 10^{4}$ packets respectively when other parameters remain fixed. As the transmission rate $(\beta)$ of node1 varies from $6 \times 10^{4}$ packets/sec to $9 \times 10^{4}$ packets/sec, the throughput of second, third nodes are constant and first node increases from $0.132 \times 10^{4}$ packets to $0.297 \times 10^{4}$ packets respectively when other parameters remain fixed. As the transmission rate of node $2(\delta)$ varies from $11 \times 10^{4}$ packets/sec to $14 \times 10^{4}$ packets/sec, the throughput of first ,third nodes are constant, second node increases from $0.594 \times 10^{4}$ to $0.966 \times 10^{4}$ when other parameters remain fixed. As the transmission rate of node $3(\theta)$ varies from $16 \times 10^{4}$ packets/sec to $19 \times 10^{4}$ packets/sec, the throughput of first node, second node is constant and third node increases from $0.512 \times 10^{4}$ packets to $0.76 \times 10^{4}$ packets when other parameters remain fixed.As the batch size distribution parameter (a1) varies from 2 to 5 , the mean delay of the first, second, third buffers increase from $0.254 \mu$ s to $0.728 \mu \mathrm{s}, 0.115 \mu \mathrm{s}$ to $0.207 \mu \mathrm{s}$ and from $0.082 \mu \mathrm{s}$ to $0.114 \mu$ s respectively, when other parameters remain fixed .As the batch size distribution parameter (b1) varies from 6 to 9 , the mean delay of the first, second node is constant and third decreases from $0.102 \mu \mathrm{s}$ to $0.098 \mu \mathrm{s}$ when other parameters remain fixed. As the batch size distribution parameter (a2) varies from 3 to 6 , the mean delay of the first is constant, second buffer decrease from $0.672 \mu$ s to $0.036 \mu$ s and third buffer increases from $0.132 \mu$ s to $0.253 \mu$ s and, when other parameters remain fixed. As the batch size distribution parameter (b2) varies from 11 to 14 the mean delay of the first, second, third node is constant, when other parameters remain fixed .When the arrival rate $(\lambda 1)$ varies from $0.5 \times 10^{4}$ messages $/ \mathrm{sec}$ to $2 \times 10^{4}$ messages $/ \mathrm{sec}$, the mean delay of the first node increase from $0.200 \mu \mathrm{s}$ to $0.208 \mu \mathrm{s}$, second, third decrease from $0.117 \mu \mathrm{s}$ to $0.113 \mu \mathrm{s}$ and from $0.103 \mu \mathrm{s}$ to $0.089 \mu$ s respectively, when other parameters remain fixed. When the arrival rate $(\lambda 2)$ varies from $1 \times 10^{4}$ messages/sec to
$2.5 \times 10^{4}$ messages/sec, the mean delay of the first node is constant ,second, third increase from $0.110 \mu \mathrm{s}$ to $0.117 \mu \mathrm{s}$, from $0.089 \mu$ s to $0.098 \mu$ s respectively, when other parameters remain fixed. As the transmission rate of node $1(\beta)$ varies from $6 \times 10^{4}$ messages $/ \mathrm{sec}$ to $9 \times 10^{4}$ messages $/ \mathrm{sec}$, the mean delay of the first node decreases from $0.167 \mu$ s to $0.111 \mu \mathrm{s}$, second and third buffers are constant when other parameters remain fixed. As the transmission rate of node $2(\delta)$ varies from $11 \times 10^{4}$ packets $/ \mathrm{sec}$ to $14 \times 10^{4}$ packets/sec, the mean delay of the first, third buffers are constant, second buffer decreases from $0.104 \mu$ s to $0.082 \mu \mathrm{s}$ when other parameters remain fixed. As the transmission rate of node $3(\theta)$ varies from $16 \times 10^{4}$ packets/sec to $19 \times 10^{4}$ packets/sec, the mean delay of the first, second buffers are constant and third buffer decreases from $0.078 \mu$ s to $0.071 \mu$ s when other parameters remain fixed
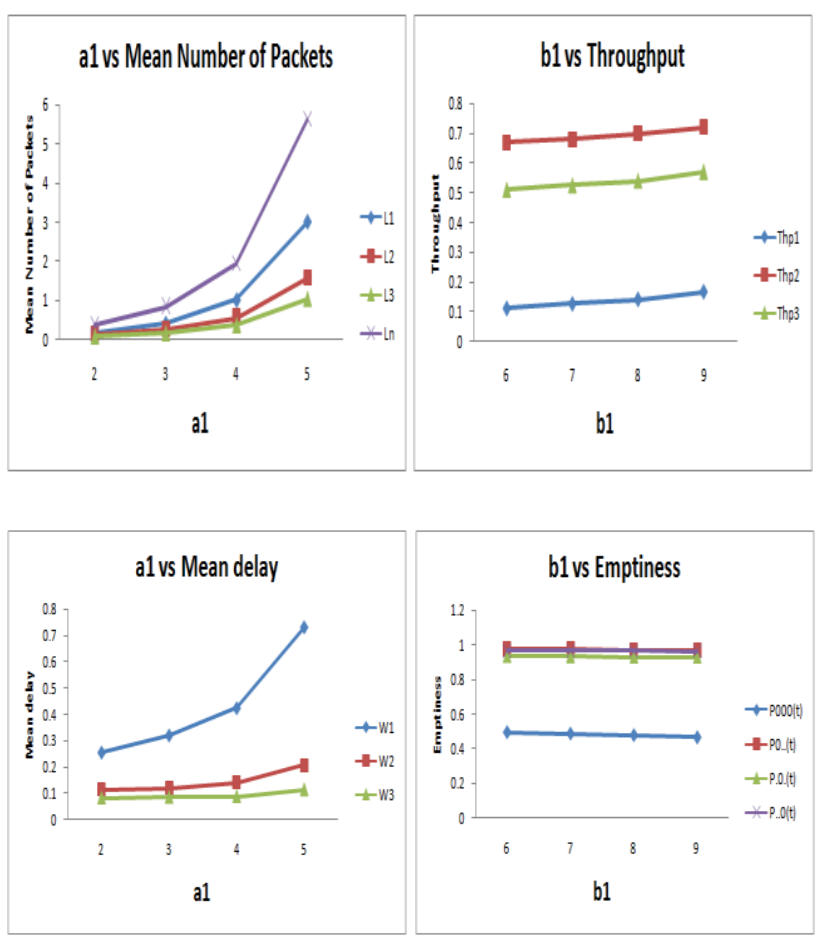

\section{Fig 2: Batch size distribution parameter a1, b1 Vs Mean Number of Packets, Throughputs, Mean delays and Emptiness in the buffers at nodes 1, 2 and 3}

Based on the analysis, this model is much useful in technological advancements and performance evaluation of communication systems for designing and developing advanced devices of communication with more effective and efficient quality of service. The DBA strategy with bulk arrivals adapted in these models was proved to reduce the burstness in buffers and mean delays through congestion control utilizing the vacant bandwidth. The bulk arrival consideration in characterizing the packet arrivals to the buffers through compound Poisson processes has a significant impact in predicting the performance measures of communication systems more accurately.

\section{CONCLUSIONS}

Performance evaluation of computer and communication networks is one of the thrust areas of computer science and engineering. Modeling of such networks and their simulations are gaining their importance in designing and developing new network architectures to meet the challenging demand for data transfer and sharing. Prediction of the performance measures 
is a challenging task for communication network operators to make available of the sufficient networks resources to fulfill the network user demand for the quality of service and the scalability of the end user networks to the communication networks. Hence, modeling of communication networks help in designing advanced communication network devices to meet the challenges in the computer and communication engineering. In this paper, an attempt is made to develop and analyze the descriptive model of communication networks with bulk arrivals and DBA under steady state conditions. It is also possible to develop and analyze the perspective modeling of communication networks with bulk arrivals and DBA using various costs and control policies. The model developed in this paper, can also be further generalized with non Marchoivian nature which require further investigations.

\section{REFERENCES}

[1] Kleinrock,L.(1976),Queuing Systems, Vol-II: Computer Applications, Wiley publications, New York.

[2] YukuoHayashida(1993), Throughput analysis of tandem typego-backNARQ scheme for satellite communications, IEEE Transactions on Communications, Vol.41, pp 15171524.

[3] Paul Dupis, Kevin Leder and Hui Wang (2007), Large deviations and importance sampling for a tandem network with slow - down, Queuing Systems, Vol.57, pp 71-83.

[4] Paul Beekhuizen, Dee Denteneer and Ivo Adan (2008), Analysis of tandem network model of a single-router network-on-chip, Annul of operations research, Vol.162, pp 19-34.

[5] Stanislav Angelov, Sanjeev Khanna, Keshav Kunal (2009), The network as a storage device: dynamic routing with bounded buffers, Algorithmica Vol.55, pp 71-94.

[6] Adan Ivo, Michel Mandjes, Werner Scheinhardt and Elena Tzenova, (2009), On a generic class of two-node queuing systems, Queuing Syst, Vol.61, pp 37-63.

[7] Sriram,K.(1993),Methodologies for bandwidth allocation, Transmission scheduling and congestion avoidance in broadband ATM networks, Computer Network, ISDN System, J.26, pp 43-59.

[8] Kin K. Leung (2002),Load dependent service queues with application to congestion control in broadband networks, Performance Evaluation, Vol.50, Issue 1-4, pp $27-40$.

[9] Kuda. Nageswara Rao, K. Srinivasa Rao, P.Srinivasa Rao (2011). Performance Evaluation of a Communication Network with Dynamic Bandwidth Allocation and Batch Arrivals, International Journal of Computer Applications (0975- 8887) Volume 16- No.8, February 2011

[10] Nakka Thirupathi Rao, K.Srinivasa Rao, Kuda Nageswara Rao and P.Srinivasa Rao (2014)-Transient Analysis of a Two Node Tandem Communication Network with Two Stage Compound Poisson Binomial Bulk Arrivals and DBA, International Journal of Computer Applications, Vol.96, No.25, pp 19-31. 